\title{
Os cinemas que falam português: o conceito de cinema nacional, identidade e resistência
}

\section{Leandro José Luz Riodades de Mendonça}

Professor doutor de Direito autoral e políticas culturais no Departamento de Artes e Estudos Culturais na Universidade Federal Fluminense (UFF) no programa de pós-graduação em Estudos Contemporâneos da UFF e no programa de pós-graduação em Políticas Públicas, Estratégias e Desenvolvimento da Universidade Federal do Rio de Janeiro. É membro da Rede Proprietas e coordena o Laboratório de Cinema e Vídeo (LCV). E-mail: leandro@vm.uff.br
Resumo: O presente artigo apresenta questões em torno do conceito de cinema nacional e suas formas de existência/resistência. Articula a dimensão espacial como limitante para o consumo dos objetos culturais, pois estes não têm livre circulação comercial. As identidades nacionais continuam a exercer pressão sob o cinema e participam da produção da representação que opera mecanismos de inclusão ou exclusão dentro de um espaço geográfico. Reflete sobre a produção cultural e as artes, pois parte da observação dos dados imediatos da realidade pensada de constrangimentos e limitações à capacidade real de produzir filmes. As limitações são, por exemplo, a capacidade técnica e o treinamento diferenciado e uma desigual capacidade de financiamento e circulação. Estes elementos redundam em produtos estéticos marcadamente diferentes.

Palavras-chave: Cinema nacional; Identidade; Modo de produção.

Title: Cinemas that speak Portuguese: the concept of national cinema, identity, and resistance

Abstract: This article presents issues surrounding the concept of national cinema as a form of existence/resistance and articulates the spatial dimension that limits the consumption of cultural objects, because they do not have free trade capacity. National identities continue to press the cinema, participating in the production of the representation that triggers inclusion or exclusion mechanisms within a geographical area, reflecting on the cultural production and on the arts by considering the observation of the immediate data from the embarrassments and limitations of the reality thought and their real capacity to produce films. The limitations are, for example, different training and expertise levels, as well as unequal financing capacity and circulation capacity. These elements redound to markedly different aesthetic products.

Keywords: National cinema; Identity; Mode of production. 
Since the end of World War II, the (West) European cinema has had its identity firmly forged by three features: its leading directors were recognized as auteurs; its styles and themes shaped the nation's self-image; and, its new waves became both: political and aesthetic renewal.

(Thomas Elsaesser, European Cinema Face to Face with Hollywood)

\section{Introdução}

A temática aqui tratada em torno do cinema nacional e suas formas de existência/ resistência é atravessada pelas discussões de um espaço de especificidade cultural que apresenta, como desdobramento importante, um rebatimento no consumo dos objetos culturais, o que altera sua possibilidade de circulação comercial e o formato dos produtos. Muitos são os motivos das transformações, desaparecimentos e ressignificações no campo das identidades, mas um deles continua a exercer imensa pressão sobre o conhecimento histórico geral e da história do cinema em particular: a ideia de nação. Ela impulsiona o motor que produz a representação, pode ser operada em mecanismos de inclusão ou exclusão e em referência a praticamente tudo em um determinado espaço geográfico. Não se restringe, entretanto, a este espaço, mas também cria identidade a partir dele. Movimenta e constrange boa parte da produção cultural e das artes e, sem dúvida alguma, a produção audiovisual. Em outras palavras, não se pode pensar em cinema nacional sem, no mínimo, inferir a ideia de nação.

Para os leitores do século XXI pode ser difícil entender o contexto do nascimento da ideia de estado-nação e sua funcionalidade nos fins do século XVIII. Claro que esta ideia-força tem desenvolvimento diferente nas várias partes do território europeu. De todo modo, uma das questões centrais é a recuperação (ou invenção) da noção de herança cultural, sendo a língua um fator determinante em muitas das vezes. Em outras palavras, a existência de um espaço linguístico comum foi, no caso europeu, diversas vezes fundamental para traçar territórios e estabelecer fronteiras entre as heranças culturais. Isso não significa afirmar que a capacidade de se expressar em determinada língua seja a única característica, mas certamente ela pode servir de ponto de partida para iniciarmos o caminho que pretendo aqui explorar.

O processo histórico faz com que várias dessas ideias-força do campo político e social acabem sendo absorvidas como senso comum ou praticamente desapareçam de nossa realidade social contemporânea. O processo de transformação do conteúdo em senso comum pode, em alguns casos, tê-lo transformado de tal maneira que teremos grande dificuldade em reconhecê-lo. Várias clivagens ideológicas acabam, com o passar do tempo, por funcionar diferentemente, seja no âmbito social ou no historiográfico e podem revelar posições bastante diversas do que significavam à época.

Os motivos destas transformações, desaparecimentos e ressignificações são muitos, mas a ideia de nação continua a exercer imensa pressão sobre o conhecimento histórico acerca do cinema. Ela ativa, ou pode ativar, um conjunto de noções de pertencimento que atravessam a representação sobre praticamente todos os objetos culturais, cria uma referência ao espaço geográfico e nele cria identidade, move e constrange de maneira significativa a produção dos filmes, sua possibilidade de circulação, fruição estética e legitimação artística. Em suma, não se pode pensar na produção audiovisual sem no mínimo inferir a ideia de nação, isto porque o financiamento, mesmo quando falamos em produção de baixo custo, depende ou de uma ação direta do estado ou de uma capacidade de circular minimamente.

A própria noção de nação, incluída na descrição do objeto, no momento de criação da história do cinema, nos força nessa direção, já que os primeiros a falar em história 
do cinema criaram também a classificação de cinemas nacionais. Isso aconteceu em parte pela observação de dados imediatos da realidade como a capacidade técnica diferenciada, a desigual capacidade de financiamento e circulação, o que redundava em produtos estéticos marcadamente diferentes assim, para termos a capacidade de definir o que é cinema, positiva ou negativamente, começamos pelo que está carregado no próprio espaço identitário nacional, estabelecendo uma ligação entre a questão nacional e a história do cinema. Essa história nos mostra que, muitas vezes, a nação determinou o estabelecimento de grupos estéticos comuns que podem ser associados às práticas de captação e de produção também próprias.

Reiteradas vezes seguidas dessa afirmação, lemos acerca da possibilidade da construção de uma história do cinema nacional (ou da arte, da música etc.), pressupondo assim certa ideia de unidade, da existência de somente uma história circunscrita ao espaço nacional. Mas, por outro lado, essa mesma história (no singular) terá de ser necessariamente múltipla diante da variedade dos modos de percepção ou representação que a atravessam e que refletem na sua especificidade, também o seu movimento de constituição. Elas, as histórias do cinema, dependem claramente das condições que foram vividas/produzidas, ou seja, por quem, em qual língua, qual espaço geográfico e, em muitos casos, da acuidade da visão e do gosto pessoal de quem a escreveu.

O que se pretende aqui é explorar inicialmente a possibilidade de estabelecermos a ligação entre as várias formas de produção de cinema praticadas onde a língua portuguesa tem influência. Esse espaço possui uma diversidade de formas de trabalho e viabilização do audiovisual que talvez possam ser interligadas de maneira transversal às várias heranças culturais, de forma a construir um valor agregador, mas, ainda assim, multipartido. Tal diferenciação serve como índice das maneiras como os conteúdos se interpenetraram e ajuda a projetar um tipo de campo da compreensão da gênese ou da real possibilidade de existência dos objetos artísticos. Explica o que realmente são e como determinaram ou foram determinadas pelo conjunto e atributos entrelaçados dos patrimônios com as obras cinematográficas.

A meu ver, o espaço nacional é o problema e também parte da solução para concatenar logicamente a reflexão acerca do audiovisual produzido com intenção comercial e autoral no centro ou na periferia dessas sociedades. Impõe a necessidade de definição com respeito ao tipo de identidades em jogo, isto é, a necessidade de tentarmos responder à pergunta sobre a existência de substância e unidade suficientemente rígidas para utilizarmos a expressão "cinemas que falam português", de modo a fazer sentido com o campo dos objetos artísticos designados. Essas são questões centrais que tudo inflexionam no sentido positivo ou negativo. Ainda mais importante é entendermos que o conteúdo da expressão "falado em português" não exprime em si mesmo uma exclusividade para o uso da língua portuguesa no audiovisual, nem define a necessidade de uma identidade linguística. Neste aspecto, podemos afirmar que na "avaliação de identidades linguísticas não se pode deixar de fazer intervir categorias como dominação cultural, sempre refletidas e sempre presentes nos discursos de que se revestem as atividades culturais e políticas" (NEVES, 2005, p. 644).

É precisoainda nos apropriarmos do polimorfismo observável no desenvolvimento e na estabilização da língua portuguesa, seja no Brasil ou seja nas outras regiões onde o idioma é falado. Devemos escrutinar o percurso de implantação da língua nesses lugares que nos mostram, pelo menos no caso brasileiro, uma bipolaridade (NEVES, 2005) na forma de lidar com o vernáculo até o final do século XIX. No período inicial do século XX, principalmente após a revolução de 30 , vemos a afirmação de uma identidade linguística que se opunha ao uso e ao ensino de outras línguas (normalmente trazidas por imigrantes) em algumas regiões do país, 
o que notadamente se vê nos estados do sul (Paraná, Santa Catarina e Rio Grande do Sul). Ainda usando o caso brasileiro como exemplo, a busca pela constituição de um padrão linguístico obedece às lógicas políticas e sociais próprias que podem ser contra a afirmação de uma identidade própria, herdada de um padrão de país branco e europeu. Este é o caso do Brasil que se aferrou ao padrão linguístico lusitano (NEVES, 2005).

Qualquer observação superficial demonstra que os espaços associados historicamente ao Império Português possuem grande variedade linguística e, talvez por isso, maneiras diversas de resistir e/ou absorver os múltiplos usos da língua. Para além de uma visão que tente criar paradigmas é preciso buscar um olhar sobre este campo específico, de maneira a preservar sua complexidade, sem destruir a centralidade das relações já existentes. $O$ caso do Brasil, onde a certeza da importância econômica do país e a passagem do tempo desde o processo de independência trabalharam para fazer desaparecer um sentimento que opusesse a língua do colonizador à identidade nacional. Se for ser cotejado com o espaço africano, onde muitas das identidades locais foram objetos de intensa repressão ainda nos anos 70 do século passado, o que veremos é uma relação profundamente diferente. A dificuldade imediata é decorrente da profundidade da reviravolta observada no que antes significava e agora significa a identidade nacional em cada um destes países e nos utilizarmos disso para entender as possíveis vinculações entre as expressões cinematográficas dos cinemas falados em português.

No século XIX, Machado de Assis cunhou a expressão 'instinto de nacionalidade' e a qual reconhece que "poesia, romance, todas as formas literárias buscam vestir-se com as cores do país" (ASSIS, 1959, s.p.). Sendo assim, o espaço nacional determina um processo de

Construção de uma nacionalidade, mais do que a defesa de uma identidade fechada ou auto-suficiente, é resultante de uma complexa trama de intercâmbios, de que são exemplos as literaturas nacionais latino-americanas no século XIX. Focalizando estas últimas, podemos ver mais facilmente que toda identidade nacional é sempre uma identidade problemática, pois não se trata de um processo que possa se estabilizar em uma solução ideal, derradeira ou definitiva. (SANTOS, 1959, s.p.)

Esse obstáculo, a impossibilidade dessa solução ideal, derradeira e definitiva traz a sensação, e mesmo a necessidade, de ver esta identidade como uma deriva sempre em movimento. Entre os tempos do Brasil colônia até a época da publicação do texto de Machado de Assis, passou-se apenas 51 anos. Aqui temos, certamente, um dado que ajuda a explicar o aparecimento do "instinto", bem como encontramos uma medida de tempo para marcar a evolução da busca identitária. Para esclarecer a visão de Machado, em outra parte o texto está indicado que a independência literária "não será obra de uma geração nem duas; muitas trabalharão para ela até perfazê-la de todo" (ASSIS, 1959, s.p.).

Foram precisos quase cem anos de independência política para que a autonomia literária fosse além da intenção programática do Romantismo do início do século XIX. Com efeito, foi a partir das obras de alguns escritores refratários à tradição acadêmico-realista, como Lima Barreto, entre outros, que se instalou parcialmente aquilo que Mário de Andrade chamaria, anos mais tarde, de "estabilização de uma consciência criadora nacional", referindo, no caso, às vanguardas modernistas da década de 1920. Todavia, esse labor de um século era naturalmente mais do que necessário, coisa confirmada pelo vaticínio do próprio Machado de Assis, que via essa independência como resultado do trabalho de várias gerações. De fato, nenhuma independência literária deriva direta e necessariamente da independência política. (SANTOS, 1959, s.p.) 
Essa trajetória dos grupos de criadores em uma determinada expressão artística foi feita com base no espaço do estado-nação, em velocidade e condições próprias. Tratou e tratará, necessariamente, não somente de questões afeitas às artes e ao audiovisual, mas também outras relacionadas à história das ideias, o que são as identidades e o que é o próprio cinema. Isso tudo é fruto das mudanças que se passaram nessas sociedades e dependente do que encaramos como nacionalidade. Para entender essas relações, é necessário desdobrar os dois contextos gerais: o primeiro se refere à falsa oposição entre arte e técnica ou entre o divertimento e a arte culta; já o segundo se refere às questões do espaço nacional como elemento que, necessariamente, constrange e delimita o espaço de ação autoral, técnica e consumo cultural.

Como sabemos, as posições que opõem estes dois campos ultrapassam em muito a questão puramente crítica, classificatória ou analítica, e representam uma tomada de posição diante da própria definição de cinema e/ou suas possíveis funções. Essa oposição é a maneira como se processa agora a redefinição do pensamento cinematográfico do início do século XX. A clivagem em questão (oposição entre arte e técnica ou entre entretenimento e arte culta) pode ter um funcionamento complementar, mas é, muitas vezes, vista como a forma central de destinar alguns dos objetos artísticos, que podem então serem postos tranquilamente fora da história oficial. $\mathrm{O}$ que ajuda a depreender a importância geral do contexto atual de existência do cinema nos distintos espaços nacionais e as, muito claramente, reduzidas possibilidades de escolha quanto a quais caminhos trilhar para fortalecer qualquer produção artística e a produção cinematográfica em particular, seja comercial seja autoral. Uma forma de entendermos essas reflexões pode surgir de questões europeias recentes; uma é a da posição das nacionalidades dentro da Europa, onde o que está em jogo são as mudanças na função da ideia de estado nacional e suas possibilidades de ação, de conformação e afirmação cultural.

Existe um raciocínio que iguala a função do estado nacional para o contexto chinês, americano, brasileiro, português ou inglês. Sabemos, entretanto, que o quesito nacional funciona, nas diversas circunstâncias nacionais, de maneira marcadamente diferente. Tomemos como exemplo a visão genérica da cultura americana fortemente transmitida pelo cinema. Ela produz uma interpretação de si mesma centrada no quadro da mescla das culturas dos imigrantes que viajaram aos Estados Unidos desde o século 17. Nesta visão agregadora, qualquer pessoa pode se tornar americana, não apenas por professar esses valores, mas também por encontrar um lugar para si mesmo no espaço da cultura americana. A nacionalidade brasileira, por sua vez, também vê como natural a ideia de o estrangeiro se tornar brasileiro, pois afirma ser essa uma característica real de sua cultura. A cultura brasileira se define como resultado do processo de absorção/ transformação do estrangeiro em brasileiro, através de lente própria, construída no processo de colonização e no percurso pós-colonial.

Muito diferente é a imagem na maioria dos países europeus que tem raízes históricas diversas. Na Europa, as definições gerais de nacionalidade vêm como dado inato e herdado pelo domínio real e imemorial de um determinado território e, a partir desse espaço geográfico, o desenvolvimento de uma identidade própria e única que resiste à transformação e/ou absorção.

A ideia das nações serem uma "peculiarity of Europe as it developed since Charlemagne" (GELLNER, 1987, p. 6) enunciada por Renan, era nova para o período do final do XIX, e, obviamente, possuía todos os defeitos do eurocentrismo do mesmo século. A obra Qu'est-ce qu'une nation de 1882, dez anos posterior ao enunciado machadiano com respeito ao "instinto de nacionalidade", interpreta e enquadra os sistemas políticos pela via europeia. Na visão de Renan, as nações são grandes lugares de solidariedade, onde este laço tem importância superior à 
identidade étnica. Tal questão será levantada na Alemanha, nação que tendia a ser delimitada como um grupo de mesma origem racial que divide características comuns como a língua. As ideias que sustentam a disputa perderam parte de sua importância com o declínio da ideia de raça. Não à toa, o termo "eugenia" foi criado em 1883 e agora está praticamente em desuso entre os antropólogos. A noção de raça como subespécie, muito difundida durante a afirmação nacional europeia substitui a noção de raça como estrangeiro; como conceito científico essa convicção caiu por terra na contemporaneidade. Não devemos, porém, deixar de notar que alguns grupos políticos da extrema direita tentem utilizá-lo e que ainda está presente em algumas legislações europeias.

Não é minha pretensão esgotar a discussão da questão, mas expor uma linha de percepção, onde se desnaturaliza o problema do estado nacional como problema unicamente da colonização que teria produzido uma unidade linguística forçada nos países que também falam português. É preciso pensar onde é central ver um antagonismo entre a unidade linguística e a existência de outros fortes grupos linguísticos. Apesar de, no contexto colonial, a rivalidade ter função política imediata, talvez a manutenção da multiplicidade das raízes linguísticas passe por um acordo sobre qual, ou se é necessária uma língua comum. Certamente a língua tem forte impacto na penetração e na possibilidade de circulação dos muitos objetos culturais e artísticos.

No caso do audiovisual, a colonização se dá pelo consumo quase que forçado de produtos importados e estandardizados. Portugal e Brasil são territórios tão colonizados como a maioria dos países; seus mercados possuem índices ainda menores de penetração para os filmes nacionais e cabe notarmos que pode ser do interesse desse colonizador/distribuidor audiovisual criar mais dificuldade para a presença de um acordo entre os países que falam português. Permaneceria a dificuldade de produzir estratégias comuns de proteção e resistência. Sem estas estratégias, pode não ser possível defender a diversidade cultural inerente a cada um desse conjunto de povos e mesmo sua diversidade linguística.

Assim, em razão das dificuldades inerentes à definição de nacional, muito precisa ser feito para o emprego do conceito a fim de articular o alcance do cinema produzido em um espaço nacional e todas as outras variáveis. A nacionalidade de um cinema não pode ser abordada isoladamente e deve se servir de aspectos práticos, onde as fontes históricas indiciem a existência de uma compressão consequente desse projeto para o desenvolvimento do fazer cinematográfico. As mudanças no cinema acompanham de diversas maneiras as profundas transformações do espaço nacional e as suas populações dos sempre se depararam com escolhas quanto aos seus rumos estratégicos, políticos ou culturais. $\mathrm{O}$ estado nacional mudou, o cinema mudou, as funções sociais dos dois campos mudaram e muitos pensam não ser importante agora o uso do conceito de nacional.

Uma questão central pode nos ajudar na compreensão: devemos tentar responder qual afinal é o valor do conceito de nacional na história do cinema? Que, a meu ver, aplica-se a muitas funções, algumas mais explícitas e outras bastante encobertas ou implícitas, mas, tão essencial hoje como foi para as primeiras formulações da história do cinema no século $X X$, e mesmo quando tentamos excluí-lo, teremos que cuidadosamente retirar todos os reflexos do nacional da nossa análise, pois, sem isso, acabamos por falar em nacionalidade involuntariamente. Esteja isso imediatamente à vista ou submerso em outros conteúdos, apareça de uma forma positiva e clara ou esteja subentendido por um discurso negativo, temos que trilhar - pelo menos superficialmente - um caminho já bastante pisado e conhecido sobre o conceito de cinema nacional.

Junto a isso, devemos buscar a recolocação da proposta de contar a história do cinema em décadas. Creio que podemos afirmar com razoável grau de certeza 
que a função e a configuração do nacional alteraram de maneira significativa dentro do fluxo das décadas. Cabe aqui um olhar mais cuidadoso a partir do pós-guerra que acaba por determinar a descolonização e o fim do domínio político de Portugal sobre Angola, Moçambique, Guiné, São Tomé e Príncipe e Cabo Verde. A presente tese aborda o fato do modo de produção de cinema em Portugal durante as décadas entre o fim da segunda guerra e a Revolução dos Cravos ter sido, de muitas maneiras, o reflexo de um longo desenvolvimento dos esforços para estabilizar uma produção que não é pensada como capaz de ocupar o mercado "contra" o cinema hegemônico, o americano principalmente. Instalase uma deriva definitiva para um tipo de cinema autoral que deve representar o ser português em sua plenitude, dentro e fora de Portugal, mas que não tem condições de circulação comercial e acaba por ser praticamente desconhecido dentro e fora do território português. Também podemos perceber um discurso semelhante na crítica brasileira, onde se valorizará as histórias e as paisagens filmadas com qualidade técnica compatível com o cinema hegemônico. Claro que essas condições estão fora do alcance de produtores periféricos e excluídos do seu próprio mercado.

\section{Sobre os modos de produzir e o cinema nacional}

O espaço contemporâneo presenciou uma reificação do termo "globalização". Muito se falou disso, sendo um dos desdobramentos a ideia de desnacionalização da estética cinematográfica. Tal posição advém da observação das novas formas de circulação dos conteúdos, da transnacionalização das estratégias de lançamento e circulação, bem como do aumento do fluxo de capitais na indústria cinematográfica. O que, entretanto, guarda uma relação intrínseca de semelhança com um fato histórico: a fortíssima pressão exercida pelo cinema americano sobre os cinemas nacionais, a partir dos anos 20. No caso europeu, é impossível não reparar que, algumas das escolhas que aparecem no centro do mesmo cenário de produção, no decorrer da primeira metade do século XX, parecem ter sido obrigadas a partir desta pressão.

Em um de seus mais belos trabalhos, Hobsbawn (1988) afirmou que:

o cinema dominaria e transformaria todas as artes do século XX [e que seu triunfo foi extraordinário e sem precedentes em termos de rapidez e escala, e em uma dúzia de anos após 1895] 26 milhões de americanos iam ver filmes toda a semana... nos 8 a 10 mil pequenos cinematógrafos [...] até na atrasada Itália havia, à época, quase quinhentos cinemas nas cidades principais [...] Essa realização extraordinária se deve, em primeiro lugar, à total falta de interesse dos pioneiros do cinema por qualquer outra coisa, além de produzir diversão lucrativa [Se continuarmos em linha com a interpretação do mencionado autor, também encontraremos a afirmação que] [...] seu público alvo era, sem a menor hesitação, os menos instruídos, os menos reflexivos, os menos ambiciosos intelectualmente, que lotavam os cinematógrafos. (p. 333)

Em síntese, é possível afirmar com razoável grau de certeza que foi um pouco o mesmo por todo lado? Ou seja, há um denominador comum em relação ao impacto do cinema no século XX? Certamente não. Os desdobramentos do cinema no centro industrial do ocidente foram muito diversos quando comparados com o que ocorreu nas periferias do sistema e podemos ver mudanças significativas de rumo entre o espaço americano de exibição e o europeu. 0 mesmo autor afirmou ainda que:

Hollywood se baseava na articulação do populismo do cinematógrafo com a mentalidade e o drama cultural e moralmente gratificantes, esperados pela massa igualmente grande de americanos médios. Sua força e sua fraqueza residiam precisamente no seu interesse único na bilheteria de um mercado de massas. A força era, em primeira instância, econômica. O cinema europeu 
optou, não sem alguma resistência da parte dos artistas populistas, pelo público culto, às custas do popular. (HOBSBAWN, 1988, p. 335)

Em outras palavras, essa opção por um cinema mais autoral feita pela Europa implicou em expandir a atuação do Estado como financiador da produção de cinema. Podermos afirmar que, de uma forma ou de outra, esta situação, mesmo que bastante alterada em algumas de suas premissas, mantém-se até a atualidade. Vale dizer que o Estado atuou de maneira diversa, dependendo da inserção própria de cada nação no mercado mundial de filmes e do interesse da elite dominante na produção cinematográfica. Nesse sentido, pode ser mesmo impossível estabelecer uma comparação, por exemplo, entre as questões que envolvem o cinema francês, o português e o inglês, dada a enorme diferença entre os meios disponíveis e a capacidade de articular-se com o cinema americano hegemônico.

O conceito de modo de produção indica que devemos reconstruir pelo menos uma parte da lógica da produção de um determinado cinema nacional para poder ver as relações existentes na capacidade de circulação e legitimação quando em um mercado ocupado pelo produto estrangeiro. É a partir desse aporte lógico que surge a sucessão de modelos de produção sobredeterminados por uma abordagem restringida pela realidade de sua capacidade de circulação. Aqui temos uma das possibilidades de explicar como e porque os filmes são como são. Não poderei realizar um triplo eixo analítico, em que estivessem articulados comercialização e recepção, exibição e as possibilidades de distribuição e os resultados em termos estilísticos e estéticos. Entretanto, deve estar clara a profunda ligação entre a história da técnica e do estilo e as relações do cinema com o conjunto da produção artística. Por fim, o estado e a política restringem a capacidade do campo cinematográfico de se interligar à sociedade e por múltiplas causas imporem organizacionalmente restrições quanto aos meios, à base industrial e técnica instalada e o seu estágio de desenvolvimento. Assim, enquanto na França temos uma luta pela recuperação de sua capacidade industrial após cada guerra, isso nunca será nem pensado em Portugal, onde o cinema industrial jamais teve lugar. A instalação de uma indústria será vista, na maioria das vezes, como complementar ao consumo de filmes estrangeiros e estes filmes serão sempre referência artística e industrial de como se deve fazer cinema.

Podemos perceber que, enquanto em cinematografias centrais encontramos muitos gêneros de filmes e considerando que é sempre entre estes gêneros que encontraremos os filmes populares de grande consumo e circulação nas áreas periféricas, esses espaços estão em permanente disputa simbólica e econômica. Tal fato implica que os formuladores das políticas de estado ou a crítica (parte integrante da legitimação de qualquer cinematografia) tem de fazer escolhas sobre o que deve ou pode ser filmado e quais os espaços disponíveis para a circulação e exibição.

A ideia de classificar um cinema nacional como gênero é fruto da naturalização de uma postura de subordinação com relação a um determinado centro produtor que dita o que é um gênero. Como já afirmado:

[o] conceito de mercadoria, na forma apreendida por Hollywood limita o espaço criativo do diretor com o estabelecimento de normas técnicas e padrões de procedimento que implicariam em um modelo geral que seria válido para todos os filmes. (KANÉ, 1974, p. 21)

Seguindo essa direção:

a especificidade de todo espaço de produção nacional é uma das limitações de que o conceito de modo de produção tenta dar conta. Ela é inerente a qualquer sistema produtivo no campo cultural que, por definição, não consegue replicar 
totalmente o produto de outro sistema produtivo, inserido em outro contexto cultural. A despeito da existência de um processo de replicação muito próximo do original, mantém-se, a meu ver, a marca indelével do processo de cópia que a tudo contamina e desvaloriza. (MENDONÇA, 2007, p. 105)

O que aparece esfumaçado por aquele tipo de raciocínio é uma dificuldade de trabalhar o tecido da cinematografia nacional em sua diversidade, pois isso não pode ser buscado apenas nos filmes sem que resulte em uma comparação sempre demeritória com um campo cinematográfico "padrão". A ideia de um cinema internacionalizado, onde comparamos filmes sem a devida percepção sobre os meios, o financiamento e sobre o suporte legislativo e estatal, o que me parece extremamente parcial. A observação dos efeitos do poder do marketing comercial ou da força da classificação e avaliação da crítica ligada aos meios de comunicação não deve nem pode ser um parâmetro totalizante da construção historiográfica do cinema.

Nas relações entre a história e a teoria do cinema, Sklar (1988) aponta que:

[uma] teoria hiperativa e uma história pouco desenvolvida não deixam espaço para o diálogo entre as duas práticas e indica mais assertivamente [...] que transações culturais ocorreram na audiência [...] entendendo a formação e a transformação cultural, o significado cultural das representações, a relação entre modos de produção cultural e recepção. (p. 22)

Neste sentido, é pertinente afirmar a capacidade de adaptação cultural da instituição cinema em sua relação com uma dada nacionalidade. Certamente a questão de um estilo cinematográfico pan-europeu baseado em coproduções reforça os motivos de se centrar na busca do entendimento de um conceito que tente trabalhar com essas características. Assim, as reações que clamam por direcionar a produção e os apoios financeiros para filmes de arte e a conjuntura decorrente desta decisão são centrais para entendermos os objetivos, tanto dos cineastas, como de agentes do campo da recepção comercial e/ou autoral como a crítica. Ainda temos as questões sobre o Estado que financia não só a produção dos filmes, como a construção e a manutenção das infraestruturas. Assim sendo, quando pensamos em um desenvolvimento historiográfico em décadas teremos momentos onde poderemos encontrar uma tentativa de consolidação de estilo dentro de uma cinematografia.

Faz sentido utilizar a cinematografia portuguesa que, a nosso ver, expôs nos anos 40 esse tipo de estabilização ao afirmar que:

a premissa de que os filmes portugueses deviam continuar a reflectir de alguma maneira sobre a identidade cultural portuguesa não só era mais antiga e mais estruturante do que se pensava, como permaneceu inabalável até muito recentemente [...] Pensar que pode não existir cinema português parece-me uma impossibilidade da mesma ordem de imaginar não existir literatura portuguesa. Trabalhar a história do cinema em grandes tendências deve também nos levar a entender como essas grandes tendências funcionaram, ou melhor, por que aconteceram. Nesta mesma direção que podemos entender como um período de 1896, termina nos anos cinquenta [ou seja, podemos ver como o grande ciclo que passa pelas] [...] pequenos filmes de Paz dos Reis às adaptações literárias do cinema mudo e das comédias populares dos anos trinta às superproduções de filmes históricos dos anos quarenta, passando pelos melodramas dos anos cinquenta [...] [carrega também um estrutura de ligação aos modos de produção que acontecem na sequência de um menor investimento do Estado para um maior, de uma legislação menos preocupada em proteger o cinema nacional para outra mais protetora, de menos treinamento e formação da mão de obra para mais investimento em conhecimento e, principalmente, demonstra uma tentativa geracional de 'criar' uma indústria de cinema em 
Portugal que funcionasse de maneira complementar e subsidiariamente ao cinema, ou cinema hegemônicos] (BAPTISTA, 2009, p. 3)

Assim, a questão de existir uma indústria de cinema nacional em qualquer um dos países que falam português será a possibilidade de encontrarmos um arrimo para sustentar a proposição das cinematografias nacionais precisarem de um ponto de inflexão, essencial para estabilizar a consciência criadora. A conclusão é que sem uma capacidade mínima de defesa da diversidade, que também existe em objetos artísticos comerciais, perdemos outras diversidades exatamente pela dificuldade de disseminar alguns dos conteúdos basais comuns às identidades em jogo. Isso significa produzir filmes que afirmem uma identidade nacional não por ser mais estável, e sim por enfeixar uma parte desses conteúdos comuns. Se for possível reunir elementos dos campos culturais envolvidos, tal identidade protegerá de alguma maneira a diversidade.

O audiovisual representa buscar tópicos que, ao serem tratados, ajudem a superar por sua representatividade e sejam capazes de enfrentar no mercado econômico e no simbólico, a cinematografia hegemônica. Devemos trabalhar ainda um pouco mais o conceito de cinema nacional. Este também vem sendo trabalhado na teoria do cinema com variados usos e um deles é a sua definição em termos econômicos. Segundo Higson (1989):

First, there is the possibility of defining national cinema in economic terms, establishing a conceptual correspondence between the terms 'national cinema' and 'the domestic film industry', and therefore being concerned with such questions as: where are these films made, and by whom? Who owns and controls the industrial infrastructures, the production companies, the distributors and the exhibition circuits? Second, there is the possibility of a textbased approach to national cinema. Here the key questions become: what are these films about? Do they share a common style or world view? What sort of projections of the national character do they offer? (p. 36)

Ao criar uma correspondência entre o termo "cinema nacional" e o de "indústria doméstica de filmes", é possível ressaltar que o conceito de cinema nacional pode ser utilizado para descrever uma coerência e uma unidade que determina a criação e a descrição de um gênero. Ademais, coloca-se em questão como:

a strategy of cultural (and economic) resistance; a means of asserting national autonomy in the face of (usually) Hollywood's international domination. [...] Histories of national cinema can only therefore really be understood as histories of crisis and conflict, of resistance and negotiation. But also, in another way, they are histories of a business seeking a secure footing in the market-place, enabling the maximisation of an industry's profits while at the same time bolstering a nation's cultural standing. (HIGSON, 1989, p. 36)

A crise e o conflito que se vê no conceito de cinema nacional também estão no conceito de identidade. O processo que vai desarticular as identidades estáveis do passado (HALL, 2003) também desarticula o conceito de cinema nacional. Se o deslocamento criado abre a possibilidade da criação de novas identidades, também deve ser mapeado quanto a sua direção, isto é, a possibilidade de deslocarmos uma identidade a fazemos mimetizar, de maneira pouco produtiva, pastiches produzidos pelo cinema hegemônico. Para a sobrevivência de um ambiente de diversidade cultural em uma extensão territorial que respeite e atue na manutenção de especificidades linguísticas e subjetivas, teremos que saber quais os pontos nodais particulares de articulação (LACLAU, 1990 apud HALL, 2003) que servirão para construir esses novos sujeitos. 
Assim se entendermos, na mesma direção de Honneth, a identidade como o reconhecimento pela socialização (HONNETH, 2003), para que ela exista é preciso que elementos subjetivos sejam compartilhados pelos sujeitos envolvidos, pois é exatamente na interação intersubjetiva que se dará um tipo de reconhecimento mútuo que sustenta a dignidade pessoal e expande a liberdade produtiva, criativa e artística. Para que estes elementos circulem em determinado meio, precisamos ainda disputar o mercado com filmes que lidem com essa preocupação de afirmação/realização. No caso, devemos pensar em entretenimento por um lado, mas em cinema autoral ou de arte por outro. Não se pode disputar o mercado somente com uma dessas características, pois isso significou e significará abdicar do confronto. Sem alguma ocupação comercial de seu próprio mercado, circulará preponderantemente o conteúdo da cultura que lidera a venda de ingressos. Assim se cumpre objetivamente dois principais objetivos: o de drenar recursos para seu próprio sistema de produção, diminuindo a quantidade de recursos disponíveis e aumentar a relevância dos seus conteúdos culturais e, com isso, ocupar o espaço de outros conteúdos que então permanecerão periféricos.

As duas maneiras nos interessam no estudo dos cinemas que falam português. Certamente, na primeira, há possibilidade da indústria de filmes ser encarada como um problema central, o que redunda em investimento no aparato técnico, seja no âmbito das instalações, seja no da formação de pessoal artístico e técnico. Sem isso não existem bases para produzir. No segundo caso, a análise do cinema de arte ou de autor tem o elemento estruturante da recepção dos filmes por um conjunto de agentes (políticos, governamentais, críticos e populares). Sem reflexão crítica que module a supremacia de conteúdos hegemônicos, o que veremos é uma comparação com o produto que tradicionalmente circula sempre desfavorável, que o considerará melhor e mais bem produzido. Os conteúdos em português não resistirão como impulsionadores da diversidade e apoios para resistência que poderia criar um modo de produção próprio.

\section{Uma conclusão, ainda que provisória}

O desequilíbrio básico que o espaço dos países que falam português enfrentam é um dos pontos centrais para entendermos as possibilidades de resistência que vise, não somente alterar a direção dos fluxos de conteúdo, mas também reconstruir o alcance da produção local. A nosso ver, as formulações sobre a identidade nacional supõem um tipo de fixidez desta identidade no passado que não veja com possível. A construção identitária existe em uma deriva constante que só pode ser bem entendida através da compreensão da direção de seu movimento. Temos que preencher a todo o tempo este espaço simbólico com a matéria que se move na sociedade. E por essa mesma razão as cinematografias desses países são tão ameaçadas.

O movimento deve ser o de reconhecer as múltiplas expressões da identidade nacional como um método para percorrer os diferentes aspectos das culturas populares. Trazer à tona, distribuir nos grandes circuitos, produzir um trânsito sobre os conteúdos periféricos para, a partir deles, desenvolver produtos que tenham vocação cultural. Essa é uma das maneiras de influenciar no sentido de instituir o reconhecimento.

Podemos nos aproveitar do conceito de imaginário como uma construção simbólica mediante a qual uma comunidade (racial, nacional, imperial, sexual etc.) se define em si mesma (MIGNOLO, 2003 apud LANDER, 2005). Para complementar esta definição, juntemos outra em que as identidades "surgem de nosso pertencimento a culturas étnicas, raciais, linguísticas, religiosas e, acima de tudo, nacionais" (HALL, 2003). Nas duas definições temos em comum uma construção simbólica que sofre e é modificada ininterruptamente por um sistema de intervenção no gosto público que visa exatamente alterar e esmaecer as especificidades naturais presentes na variedade de recepções possíveis a um objeto cultural. Assim, esse sistema procura impor uma subjetividade que se 
espalha, atravessa o sujeito e constrói em torno dele uma noção de pertencimento falsa e, ainda por cima, desloca a visão da sociedade sobre esse sujeito na direção de desvalorizar sua produção simbólica em troca de outra.

Tais movimentos são encarados como um fluxo natural do centro para a periferia que atua por toda a sociedade de maneira insidiosa para, nas muitas direções em que opera, aparecer de maneira sub-reptícia em múltiplas visões que terão de ser desmontadas cuidadosamente pelos agentes da periferia para que suas obras adquiram estatuto artístico. Retornando ao audiovisual, podemos afirmar que os diferentes níveis de exibição e a não existência de um circuito exibidor audiovisual em que exista mais diversidade é, sem nenhuma dúvida, um aspecto redutor da capacidade de uma sociedade de gerar autoreconhecimento e, por essa razão, redutor da capacidade de produção de conteúdo.

\section{Referências Bibliográficas}

ASSIS, M. Instinto de Nacionalidade. In: - Machado de Assis: crítica, notícia da atual literatura brasileira. São Paulo: Agir, 1959, p. 28-34. Disponível em: <http://www.ufrgs.br/cdrom/assis/massis.pdf>. Acesso em: out. 2013.

BAPTISTA, T. Nacionalmente correcto: a invenção do cinema português. Revista Estudos do Século XX, Coimbra, Portugal, n. 9, p. 305-324, 2009.

GELLNER, E. Culture, identity, and politics. Cambridge: Cambridge University Press, 1987.

HALL, S. A identidade cultural na pós-modernidade. Rio de Janeiro: DP\&A, 2003.

HIGSON, A. The concept of national cinema. Screen, Oxford, Inglaterra, v. 30, n. 4, p. 36-47, 1989.

HOBSBAWN, E. A era dos impérios. Rio de Janeiro: Paz e Terra, 1988.

HONNETH, A. Luta por reconhecimento: a gramática moral dos conflitos sociais. São Paulo: Editora 34, 2003.

KANÉ, P. Cinema, arte e ideologia. Porto: Afrontamento, 1974.

LANDER, E. (Org.). A colonialidade do saber: eurocentrismo e ciências sociais Perspectivas latino-americanas. Argentina: Clacso, 2005. Disponível em: <http:// www.geografia.fflch.usp.br/graduacao/apoio/Apoio/Apoio_Tonico/2s2012/ Texto_1.pdf>. Acesso em: out. 2013

MENDONÇA, L. J. R. Cinema e indústria: o conceito de modo de produção cinematográfico e o cinema brasileiro. 2007. 180f. Tese (Doutorado em Estudo dos Meios e da Produção Midiática) - Escola de Comunicação e Artes, Universidade de São Paulo, São Paulo, 2007.

NEVES, M. H. M. O Brasil no contexto da construção de uma identidade lingüística no mundo lusófono In: RIO-TORTO, G. M. O.; FIGUEIREDO, O. M. S. (Org.). Estudos em homenagem ao Professor Doutor Mário Vilela. Porto: Faculdade de Letras da Universidade do Porto, v. 2, p. 643-656, 2005.

SANTOS, A. L. Instinto de Nacionalidade: Hipertexto. In: ASSIS, M. Machado de Assis: crítica, notícia da atual literatura brasileira. São Paulo: Agir, p. 28-34, 1959. Disponível em: <http://www.ufrgs.br/cdrom/assis/massis.pdf>. Acesso em: out. 2013.

SKLAR, R. Oh! Althusser!: Historiography and the rise of cinema studies. Radical History Review, Carolina do Norte, Estados Unidos da América, n. 41, p. 10-35, abr. 1988. 